\title{
Piyu Yue
}

Piyu Yue, a research associate at the $1 C^{2}$ Institute, University of Texas as Austin, was a visiting scholar at the Federal Reserve Bank of St. Louis when this article was written. Lym Dietrich provided research assistance. The author wishes to thank Professor Leon Lasdon for the GRG2 Fortran code and Professor Douglas Fisher for providing the data. Estimations that appear in this anticle were calculated at the University of Texas at Austin and are the responsibility of the author.

\section{A Microeconometric Approach to Estimating Money Demand: The Asymptotically Ideal Model}

$\mathbf{T}$ analysis, the demand for real money balances is typically expressed as a function of such variables as real income, the expected rate of inflation and the nominal interest rate. ${ }^{1} \mathrm{Em}$ pirical investigations using these variables have not been particularly useful in predicting the demand for money or in formulating and evaluating monetary policy. ${ }^{2}$

More recently, a number of researchers have attempted to estimate money demand in a manner consistent with microeconomic foundations.
Even in these cases, however, the empirical results have been largely discouraging. ${ }^{3}$

This paper reviews the general micro-econometric approach to estimating the demand for money, culminating with an advanced micro. econometric model, called the Asymptotically Ideal Model (AIM). AIM is applied to U.S. timeseries data and the results are compared briefly with those from previous studies. AlM results are consistent with microeconomic theory and provide insight into the behavior of money demand in the 1970 s and 1980 s.
See Friedman (1956) for one of the most comprehensive discussions of the money demand function.

2These functions have been subject to several unexplainable shifts and often imply a larger liquidity effect than is typically experienced. Perhaps the most dramatic example of this phenomenon occurred in the early 1980 s with the yet unexplained break in the income velocity of M1. For this and other examples, see Goldteld (1976), Friedman (1984), Lucas (1988) and Rasche (1990).
${ }^{3}$ Frequently, the estimated own price elasticities of demand for monetary assets are positive, implying that their demand curves slope upward. For example, see Serletis (1988), Fisher (1989) and Moore, Porter and Small (1990). 


\section{MUROECONOMIC MODELING}

As a result of developments in macroeconomic theory over the past two decades, "almost all macroeconomists agree that basing macroeco. nomics on firm microeconomic principles should be higher on the research agenda than it has been in the past." " Problems arise, however, when aggregate, macroeconomic data are used to estimate microeconomic-based models of money demand. Some of these problems are illustrated by a simple example that uses two approaches to microeconomic modeling: the demand function approach and the utility function approach. ${ }^{5}$

\section{The Demand Function Approach}

Consider al economy where the representa. tive consumer allocates income between a composite consumer good, $A$, and a monetary asset, $M$, that yields monetary services. The consumer's objective is to maximize the utility function (subject to a budget constraint), given the price of the composite commodity and the user cost of the monetary asset. Let $P, u$ and $E$ denote the price level (the price of $A$ ), the nominal user cost of holding one real unit of $\mathrm{M}$ and total expenditures (or income), respectively. ${ }^{6}$ The consumer's decision problem is expressed by

$$
\begin{aligned}
& \operatorname{Max} f(A, M)=A^{r} M^{1-r}, \\
& \text { subject to PA }+u M=E .^{7}
\end{aligned}
$$

For simplicity, the utility function, is is CobbDouglas, where $r$, an unknown parameter, characterizes the consumer's taste or preference. The optimal solution to the consumer's de* cision problem yields ordinary demand functions for $A$ and $M$. In this case, the demand functions are:

(1) $A=r E / P=\Gamma /(P / E)=G_{1}(u / E, P / E, r)$, and

(2) $M=(1-\Gamma) E / U=(1-r) /(U / E)=G_{2}(U / E, P / E, r)$.

The demands for $A$ and $M$ are functions, $G_{1}$ and $G_{2}$, respectively, of $E, P, \mathbf{L}$ and the unknown parameter $r$. Because the budget constraint is linear in $\mathrm{P}$ and $\mathrm{u}$, the normalized price, $\mathrm{P} / \mathrm{E}$, and user cost, $\mathrm{w} / \mathrm{E}$, can replace $\mathrm{P}, \mathrm{u}$ and $\mathrm{E}$. In general, demand functions can be expressed by nor. malized prices (including the user cost) and the unknown parameter. This parameter can be estimated by simultaneously fitting equations (1) and (2) using data on real quantities of $A$ and $M$ and the normalized price and user cost.

This approach is called the "demand function" approach because estimation begins after demand functions are specified. For this approach to yield meaningful estimates, however, the specified system of demand functions must correspond to the neoclassical utility function from which they were derived. Consequently, the conditions for estimating the system of demand functions are fairly restrictive. For instance, the Rotterdam model (a well-known demand system used in empirical studies) requires specific forms for demand functions and specific constraints on parameters during estimation. ${ }^{8}$

Even if these conditions are satisfied, however, the Rotterdam model is still highly restrictive because the assumed underlying utility function (either Cobb-Douglas or CES) is a member of a narrow class of utility functions with constant elasticities of substitution. ${ }^{9}$
"Mankiw (1990), page 1658.

sSome economists argue that aggregate data cannot be applied to microeconomic models without considering the problems of aggregation. Aggregation problems are not discussed in this paper, although the aggregation error might be one source of the unsatisfactory performance of conventional money-demand functions.

The user cost of holding a unit of a real monetary asset is computed by the formula,

$u=p^{*}(t)[R(t)-i(t)] /[1+R(t)]$, where $p^{*}(t)$ is the "true" cost of living index defined as the geometric average of the constmer price index and the consumption goods deflator, $R(t)$ is the benchmark interest rate or the maximum rate in the economy at each period and $i(t)$ is the interest rate on the monetary asset. The formula is derived from a widely applicable consumer decision model.

${ }^{7}$ Distinct views about money have resulted in two approaches to analyzing consumer demand for money. In the first approach, money is viewed as a commodity which provides a monetary service flow to holders. Thus, real balances of the monetary assets directly enter the con- sumer's utility function along with reas consumption. In the other approach, money is viewed as intrinsically worthless; consumers hold it only to finance current and future consumption. As a result, real money balances do not enter the consumer's utility function per se. Instead, the liquidity cost of holding real money balances is taken into account in the budget constraint. Feenstra (1986) shows that these two approaches are equivalent.

${ }^{8}$ For an application of the Rotterdam model to the moneydemand system, see Fayyad (1986). For the theory of the Rotterdam model, see Barnett (1981).

It is easy to encounter difficulties using the demand function approach. The failure to specify functions correctly or impose relevant restrictions can result in biased or inelficient parameter estimates. 


\section{The Utility Function Approach}

The utility function approach to demand estimation also has been used in empirical studies. To understand this approach, reconsider the consumer's decision problem and the demand functions shown in equations 1 and 2 . In the utility function approach, demand functions for $A$ and $M$ are substituted into the utility function, $f(A, M)$, to obtain the indirect utility function,

$$
h\left(v_{1}, v_{2}, r\right)=f\left[A\left(v_{1}, v_{2}, r\right), M\left(v_{2}, v_{2}, r\right)\right]
$$

where $v_{1}=P / E, v_{z}=U / E$. Because the indirect utility function has properties that are the inverse of those for the utility function, it is more convenient to use the reciprocal of the indirect utility function,

$$
\mathrm{F}\left(\mathrm{v}_{1}, \mathrm{v}_{2}, \mathrm{r}\right)=1 / \mathrm{h}\left(\mathrm{v}_{1}, \mathrm{v}_{2}, \mathrm{r}\right) .^{10}
$$

By definition, demand functions can be expressed in terms of their expenditure shares, $s_{1}=A P / E$ and $s_{2}=$ Mu/E. That is,

$$
A \equiv \mathrm{s}_{1} / \mathrm{v}_{1} \text { and } \mathrm{M} \equiv \mathrm{s}_{2} / \mathrm{v}_{2} \cdot{ }^{12}
$$

In this way, demand functions can be obtained without solving first-order conditions. Consequently, no matter how complicated the utility function might be, the derivation of share equations and demand functions is straightforward.

Of course, if the utility function is relatively simple and well-behaved (for example, when the Cobb-Douglas function is used), there is no need to use the utility function approach. However, if the utility function includes more than two goods or is sufficiently complicated, the Lagrange multiplier procedure cannot be used to derive demand functions.

\section{THE SEMI-NONPARAMETRIC METHOD FOR ESTIMATING THE DEMAND SYSTEM}

The critical step in applying the utility function approach is the specification of the proper reciprocal indirect utility function, $F$. To simplify the terminology, the term "utility function" will indicate "the reciprocal of the indirect utility function" in the following discussion.

\section{Flexible Functional Forn Modeling}

Cobb-Douglas and CES functions have been used extensively in theoretical and applied work becatse of their relative simplicity. Despite their apparent successes, however, such use has been criticized. For example, if there are more than two goods, the CES utility function can only generate demand systems when each pair of goods has the same constant elasticity of substitution. ${ }^{12}$ Unless there is prior information to the contrary, however, the elasticities of substitution should be determined by the data rather than restricted by the specification of the utility function. This limitation has motivated researchers to look for utility functions that are more flexible and allow for data-determined elasticities of substitution.

Flexible functional form models have attracted considerable attention in economics literature since the early 1970s, when it was proposed that the translog and generalized Leontief functions should replace neoclassical utility functions. It was recognized that the values of the elasticities of substitution are determined by the value of the utility function and the values of its first- and second-order derivatives are evaluated at its extreme point. Consequently, if the values of the utility function and these derivatives can be estimated, so too can the elasticities of substitution. This idea forms the basis for the flexible functional form approach.

A functional form is said to be flexible if its level and the first- and second-order derivatives at a point in its domain are allowed to reach the respective values of the "true" utility function at that point. The true utility function is assumed consistent with the properties of the data, so that, in principle, elasticities of substitution consistent with the data can be estimated.
10The duality theory states that if the reciprocal of the indifect utility function, $F$, is nondecreasing and quasiconcave with respect to normalized prices, the respective utility function, $f$, must be nondecreasing and quasiconcave with respect to quantity variables. In this sense, the utility function is equivalent to its reciprocal indirect utility function.

11Expenditures shares can be obtained by using the modi- fied Roy's identity from duality theory. That is,

$s_{i}=\left(v_{i} d F / d v_{i}\right) / V^{\prime} \nabla F(V, r), i=1,2$,

where the vector $V^{t}=\left(v_{1}, v_{2}\right)$ and the gradient vector

$\nabla F(V, r)=\left(d F / d v_{1}, d F / d v_{2}\right)^{\prime}$. See Diewert $(1974)$.

12See Uzawa (1962). 
One flexible functional form is derived from a Taylor series expansion where all terms greater than second-order are eliminated, that is,

(3) $\mathrm{F}=\mathrm{a}_{0}+\sum_{\mathrm{j}} \mathrm{a}_{\mathrm{i}} \mathrm{x}_{\mathrm{i}}+\Sigma_{\mathrm{i}} \Sigma_{\mathrm{j}} \mathrm{a}_{\mathrm{i}} \mathrm{x}_{\mathrm{i}} \mathrm{x}_{\mathrm{j}} \cdot{ }^{13}$

This approximation is flexible because it has enough free coefficients, $a_{0}, a_{i}, a_{i j}$, to allow for any desired value of the first- and second-order derivatives of function $F$,

Two frequently used flexible functional forms, the translog and generalized Leontief functions, are given by simple substitution into equation 3 . For the translog function,

$$
F=\ln (f(x)) \text { and } x_{1}=\ln (q),
$$

where $f$ denotes the utility function and $q_{1}$ represents the quantity of good i. The generalized Leontief function is attained by letting

$$
F=(f(x))^{1 / 2} \text { and } x_{1}=\left(q_{i}\right)^{1 / 2} \text {. }
$$

The coefficients in these functional forms can be estimated and in turn, the demand system and the elasticities of substitution can be derived.

\section{Caveats For Flexible Functional Forms}

Theoretically, the second-order Taylor approximation can attain flexibility only at a single point or in an infinitesimally small region. Hence, estimates of the elasticities of substitu. tion are valid only for the range of observations covered by the sample data. Therefore, the second-order Taylor series approximation should be viewed as "locally flexible."

Such models are also subject to another, potentially more serious, problem. Experience has demonstrated that regularity conditions are frequently violated! Therefore, the restrictions that microeconomic theory imposes on con-

13This equation is written in general form, where $\mathrm{a}_{0}$ denotes all the constants that is, the function evaluated at the point of interest and the partial derivatives evaluated at the same point). The use of this general form to estimate these equations is one of the procedure's limitations because the point about which the expansion is made is estimated by the daia, rather than being specified by the researcher. Hence, there is no guarantee that this point will necessarily correspond with the maximum value of the function itself.

14The regularity region is the subset of the domain of the utility function in which all regularity conditions are satisfied. sumer behavior are not embedded in these flex. ible functional forms. This point is illustrated later in the empirical section of this paper.

In an attempt to solve these problems, micro. economists have developed a variety of flexible functional forms that maintain their flexibility and have larger regularity regions. ${ }^{14} \mathrm{~A}$ family of such flexible functional form models has been proposed (for example, Barnett's (1981) minflex Laurent model). ${ }^{15}$ To gain global regularity, however, additional constraints are imposed on the parameters which result in a loss of local flexibility. This tradeoff between flexibility and regularity is characteristic of flexible functional form modeling. None of these models is both globally regular and globally flexible. ${ }^{16}$

\section{Semi-nonparametric Method}

Gallant (1981) created the "semi-nonparametric method" to remove the local flexibility limita. tion. His method specifies a series of models that approximate the underlying utility function at every point in the function's domain. Hence, the models are globally flexible.

The "semi-nonparametric method" is built upon a well-known result in mathematics: a Fourier series expansion can converge to any continuous function. ${ }^{17}$ In contrast to the local convergence of the flexible functional forms, the Fourier series can approximate a continuous function in the entire domain. Gallant proposed to use the Fourier series expansion to specify a series of utility functions that can converge to any neoclassical utility function. Because neoclas. sical functions are a subset of continuous functions, the property of the Fourier series expansion will guarantee asymptotic convergence to an underlying neoclassical utility function.

Fourier series modeling consists of a series of expansions of models, with succeeding models nested in the preceding one. When the sample size increases, higher-order models can be speci-

15Instead of the Taylor series expansion, Bamett used the Laurent expension to enlarge the regularity region and maintain enough parametric freedom to satisfy requirements for flexibility. See Barneit (1983).

${ }_{16}$ See Diewert and Wales (1987).

7 The function must be integrable or, more generally, it must fle in a Hibert space. See Telser and Graves (1972). 
fied by simply adding more terms of the component functions. For instance, the first-order model is defined by the utility function,

$$
\begin{aligned}
F= & a_{0}+\sum_{i} a_{i} q_{i}+\sum_{i} \sum_{i} a_{i j} q_{i} q_{i}+\sum_{i} b_{i} \cos \left(\Omega q_{i}\right) \\
& +\Sigma_{i} d_{i} \sin \left(\Omega q_{i}\right) .
\end{aligned}
$$

The $j^{\text {th-order }}$ model is defined by the utility function,

$$
\begin{aligned}
F= & a_{0}+\Sigma_{i} a_{i} q_{i}+\Sigma_{i} \Sigma_{i j} a_{i j} q_{i} q_{i}+\Sigma_{i} \sum_{i} b_{i j} \cos \left(j \Omega q_{j}\right) \\
& +\Sigma_{i} \Sigma_{j} d_{i j} \sin \left(j \Omega q_{i}\right) .
\end{aligned}
$$

Asymptotically, the model contains an infinite number of terms and unknown parameters. Therefore, asymptotic inference based upon the Fourier series expansion models is free from functional-form specification error. This is its principal advantage.

In empirical work, however, the number of terms must be finite. Consequently, the properties of lower-order Fourier models become decisive. The harmonic component functions, such as sines and cosines which are frequently used in engineering and physics, are not suitable in economic applications because they do not satisfy the usual regularity conditions, such as monotonically increasing and strictly quasiconcave. This means that lower-order Fourier series models can violate regularity conditions. ${ }^{18}$ Nevertheless, Gallant's approach permitted micro-econometric models to achieve both global regularity and global flexibility.

\section{The AM Demand System}

To solve the problems of Fourier series models, another infinite function series, called the Muntz-Szatz series, is adopted. A typical form of the series is expressed as:

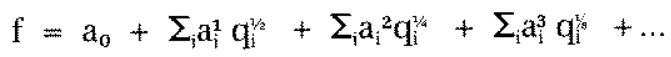

$$
\begin{aligned}
& +\sum_{i} \sum_{j} a_{i j}^{1} q_{i j}^{1 / 2} q_{j}^{3 / 6}+\sum_{i} \sum_{j} a_{i j}^{2} q_{i j}^{1 / 2} q_{i}^{1 / 2}+\ldots \\
& +\Sigma_{i} \Sigma_{i} b_{i j}^{1} q_{i}^{j / 4} q_{i j}^{1 / 4}+\Sigma_{i} \Sigma_{i j} b_{i j}^{2} q_{i}^{1 / 4} q_{i}^{1 /}+\ldots
\end{aligned}
$$

The Muntz-Szatz series expansion converges to a continuous function, and any continuous function can be approximated by the Muntz-
Szatz series. ${ }^{19}$ Consequently, this series can be used to approximate a neoclassical utility function asymptotically. ${ }^{20}$

The Muntz-Szatz series is a linear combination of a set of special power functions. In contrast to the Fourier series, the component functions of the Muntz-Szatz series, $\mathrm{q}_{i}^{1 / 2}, \mathrm{q}_{i}^{3 / 4}, \ldots, \mathrm{q}_{i}^{1 / 2} \mathrm{q}_{j}^{3 / 2}, \ldots$, are neoclassical functions. In other words, they are monotonically increasing and quasi-concave with respect to variables $q_{i}$ and $q_{i}$. The MuntzSzatz series is necessarily neoclassical, however, only if all of the coefficients, $a_{i}, a_{i j}^{k}, b_{i j}^{k}, \ldots$, are non-negative, because only positive linear combinations of the neoclassical component functions are necessarily neoclassical. As a result, the coefficient-restricted Muntz-Szatz series can approach a neoclassical function but may not approach any continuous function. Imposing these restrictions guarantees that the estimated function will not violate regularity conditions.

The Muntz-Szatz series is used in place of the Fotrier series in Gallant's semi-nonparametric method. A series of models can be defined by increasing degrees of the Muntz-Szatz approximations. Under the parameter constraint, these models are globally regular; the respective utility functions are neoclassical everywhere in their domain. When the sample size increases, higher. order models can be specified with more free parameters to best fit the data and derive the elasticities of substitution that the data suggest. Hence, the Muntz-Szatz series gives rise to a model that is asymptotically globally flexible. Even a low-order approximation requires a fairly large number of parameters to be estimated, however. Hence, while the model is asymptotically globally flexible, finite samples will limit the researcher's ability to fully utilize this property.

The model has two additional features that make it particularly attractive for applied work. First, although there are a relatively large number of free parameters to be estimated, it is impossible to overfit the noise in the data. Because movements due to measurement errors are irregular and cannot be expressed by the neoclassical component functions, the model simply

19Once again, the function must be integrable or, more generally, lie in a Hibert space. See Telser and Graves (1972).

20See Barnett and Jonas (1983).
${ }_{18}$ Moreover, the Fourier series models can easily overfit the noise of the data. Usually, the measurement errors of ecom nomic variables can be decomposed into a pure white noise plus some high-frequency periodic tunctions. These latter functions might be mistaken for useful information if their frequencies are close to that of the sine and cosine functions in the Fourier series models. 
ignores them. Also, because the component functions are not periodic, the high-frequency, periodic movements in the data are likewise ignored.

Consequently, models based on the MuntzSzatz series expansion are globally regular and are asymptotically globally flexible. This is why they are called Asymptotically Ideal Models (AIMs). ${ }^{21}$

\section{ESTIMATION OF THE AM MONEV DEMAND SVSTEM}

Four subaggregated goods are included in the empirical work presented here: a consumer good, $A_{4}$, and three monetary assets, $A_{1}, A_{2}$ and $A_{3} . A_{4}$ is an aggregate good of consumer durables, nondurables and services and its respective aggregate price is denoted by $\mathrm{p}^{*} \mathrm{~A}_{1}$ consists of currency, demand deposits of households and other checkable deposits; $A_{2}$ is composed of savings deposits at commercial banks and thrifts, super NOW accounts and money market deposit accounts; and $A_{3}$ is small time deposits at commercial banks and thrifts. ${ }^{22}$ For each subset, an aggregate quantity is defined as a sum of per capita real balances of the component monetary assets. ${ }^{23}$ The opportunity cost of holding a unit of a real monetary asset is measured by its user cost, a quantity-share-weighted sum of the individual user costs that compose it. The user cost of $A_{i}$ is denoted by $u_{i}$.

The representative consumer solves an optimal allocation problem by selecting real consumption, $A_{4}$, and real balances of the monetary assets, $A_{1}, A_{2}$ and $A_{3}$, to maximize the utility function $f\left(A_{1}, A_{2}, A_{3}, A_{4}\right)$, subject to the budget constraint, given $\mathrm{p}^{*}, \mathrm{u}_{1}, \mathrm{u}_{2}, \mathrm{u}_{3}$ and the total expenditure, E. Following the utility function approach and using the first-order AIM model, we specify the reciprocal indirect utility function for the four goods case as:

$$
\begin{aligned}
& F(v, a)=a_{1} v_{t}^{1 / 2}+a_{2} v_{2}^{1 / 2}+a_{3} v_{3}^{1 / 2}+a_{4} v_{4}^{1 / 2} \\
& +a_{5} v_{1}^{1 / 2} v_{2}^{1 / 2}+a_{6} v_{1}^{1 / 2} v_{3}^{1 / 2}+a_{7} v_{1}^{1 / 2} v_{4}^{1 / 2} \\
& +a_{8} v_{2}{ }^{3 / 2} v_{3}^{3 / 2}+a_{9} v_{2}^{1 / 2} v_{4}^{1 / 2} \\
& +a_{10} v_{3}^{1 / 2} v_{4}^{1 / 2}+a_{11} v_{1}^{1 / 2} v_{2}^{1 / 2} v_{3}^{1 / 2} \\
& +a_{12} v_{1}^{1 / 2} v_{2}^{3 / /} v_{4}^{3 / 2}+a_{13} v_{1}^{1 / 2} v_{3}^{1 / 2} v_{4}^{3 / 2} \\
& +a_{14} v_{2}^{1 / 2} v_{3}^{3 / 2} v_{4}^{1 / 2}+a_{15} V_{1}^{1 / 2} v_{2}^{1 / 4} V_{3}^{1 / 2} V_{4}^{1 / 2} \text {, }
\end{aligned}
$$

where $v_{1}, v_{2}, v_{3}$ and $v_{4}$ are the normalized prices, and $a_{1}, a_{2}, \ldots$, and $a_{15}$ are the parameters of the indirect utility function.

The share equation for each good is derived from equations 3 using the modified Roy's identity. These are

$$
\begin{aligned}
& \mathrm{s}_{1}=\mathrm{S}_{1} / \mathrm{S}, \mathrm{s}_{2}=\mathrm{S}_{2} / \mathrm{S}, \mathrm{s}_{3}=\mathrm{S}_{3} / \mathrm{S}, \text { and } \mathrm{s}_{4}=\left(1-\mathrm{s}_{1}\right. \\
& -s_{2}-s_{3} \text { ), where } \\
& S_{1}=a_{1} v_{1}^{1 / 2}+a_{5} v_{1}^{1 / 2} v_{2}^{1 / 2}+a_{6} v_{1}^{1 / 2} v_{3}^{1 / 2}+a_{7} v_{1}^{1 / 2} v_{4}^{3 / 2} \\
& +a_{11} V_{1}^{1 / 2} V_{2}^{1 / 2} V_{3}^{1 / 2}+a_{12} V_{1}^{1 / 2} V_{2}^{1 / 2} V_{4}^{1 / 2}
\end{aligned}
$$

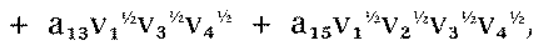

$$
\begin{aligned}
& S_{2}=a_{2} v_{2}^{1 / 2}+a_{5} v_{1}^{1 / 2} v_{2}^{3 / 2}+a_{8} v_{2}^{1 / 2} v_{3}^{1 / 2}+a_{9} v_{2}^{1 / 2} v_{4}^{1 / 2} \\
& +a_{11} v_{1}^{1 / 3} v_{2}^{1 / 2} v_{3}^{1 / 3}+a_{12} v_{1}^{1 / 2} v_{2}^{1 / 2} v_{4}^{1 / 2} \\
& +a_{14} v_{2}^{3 / 2} V_{3}^{1 / 2} V_{4}^{1 / 2}+a_{15} v_{1}^{3 / 2} v_{2}^{1 / 2} V_{3}{ }^{3 / 2} V_{4}^{1 / 2} \text {, } \\
& S_{3}=a_{3} v_{3}^{1 / 5}+a_{6} v_{1}^{1 / 2} v_{3}^{1 / 2}+a_{8} v_{2}^{1 / 2} v_{3}^{1 / 2}+a_{10} v_{3}^{1 / 3} V_{4}^{1 / 2} \\
& +a_{11} v_{1}{ }^{3 / 4} v_{2}^{1 / 2} v_{3}^{1 / 2}+a_{13} v_{1}^{3 / 3} v_{3}^{1 / / 2} v_{4}^{1 / 2} \\
& +a_{14} v_{2}^{1 / 3} v_{3}^{1 / 2} v_{4}^{1 / 2}+a_{15} v_{1}^{1 / 2} v_{2}^{1 / 2} v_{3}^{1 / 2} v_{4}^{1 / 2} \text { and } \\
& \mathrm{S}=\mathrm{a}_{1} \mathrm{v}_{1^{1 / 2}}+\mathrm{a}_{2} \mathrm{v}_{2}{ }^{1 / 2}+\mathrm{a}_{3} \mathrm{v}_{3}{ }^{1 / 2}+\mathrm{a}_{4} \mathrm{v}_{4}^{1 / 2}+2 \mathrm{a}_{5} \mathrm{v}_{1}^{1 / 2} \mathrm{v}_{2}^{1 / 2} \\
& +2 a_{6} v_{1}^{1 / 2} v_{3}^{1 / 2}+2 a_{7} v_{1}^{1 / 2} v_{4}^{1 / 2}+2 a_{8} v_{2}^{1 / 2} v_{3}^{1 / 2} \\
& +2 a_{9} v_{2}^{1 / 2} v_{4}^{1 / 3}+2 a_{10} v_{3}^{1 / 2} v_{4}^{1 / 2}+3 a_{11} v_{1}^{1 / 2} v_{2}^{1 / 2} v_{3}^{1 / 2} \\
& +3 a_{12} v_{1}^{1 / 2} v_{2}^{1 / 2} v_{4}^{1 / 2}+3 a_{13} v_{1}^{1 / 3} V_{3}^{1 / 2} V_{4}^{1 / 2} \\
& +3 a_{14} v_{2}^{1 / 2} v_{3}^{1 / 2} v_{4}^{1 / 2}+4 a_{15} v_{1}^{1 / 2} v_{2}^{1 / 2} v_{3}^{1 / 2} v_{4}^{1 / 2 / 2} \text {. }
\end{aligned}
$$

Only the first three share equations are independent and can be written generally as:

(4) $\mathrm{s}_{\mathrm{i}}=\mathrm{S}_{\mathrm{i}} / \mathrm{S}=\mathrm{g}_{\mathrm{i}}(\mathrm{v}, \mathrm{a})$ for $\mathrm{i}=1,2,3$.

When the additional parameter normalization $a_{2}$ $+a_{2}+a_{3}+a_{4}=1$ is imposed, one parameter, for example $a_{4}$, can be eliminated by substitu-

this is the case, the demand system of consumption and the subaggregate $M 2$ monetary assets are the appropriate way to study demand for money in terms of the economic aggregation theory.

${ }^{23}$ The reader is cautioned that these results are not directly comparable with those using conventional money demand specifications because the latter employ conventional monetary aggregate data that differ in several respects from those used here. First, business demand deposits are excluded from the data used here, so that $M 1$ is not equal to $A_{1}$ and $M 2$ is not equal to $A_{1}+A_{2}+A_{3}$. Moreover, unlike the conventional monetary aggregates, each of the sub-aggregates is seasonally adjusted separately. 
tion. Hence, in the case of four goods, the firstorder AIM system contains 14 free parameters. ${ }^{24}$

The share equations are nonlinear with respect to the normalized prices and hence, to income and prices as well. By the definition of expenditure shares, demand functions can be expressed as $A_{1}=s_{i} / v_{i}$. The complicated nonlinearity of the share equations, however, makes it impossible to derive a closed-form expression for the demand functions, such as the conventional linear or log-linear functions of income, prices and interest rates. Fortunately, the estimated parameters and share equations can be used to compute the income and price elasticities for consumer goods and monetary assets.

\section{Estimation of the AIM Demand System}

The AIM model is estimated by a maximum likelihood procedure under the assumption that each share equation in (4) has an additive error term, $\varepsilon_{\mathrm{i} t}$. That is,

(5) $\mathrm{s}_{\mathrm{i}}=\mathrm{g}_{\mathrm{i}}(\mathrm{v}, \mathrm{a})+\varepsilon_{\mathrm{it}}, \mathrm{i}=1,2,3$.

The disturbances are assumed to be independent and identically distributed multivariate normal random variables with zero mean and covariance matrix $\Sigma$. The sample disturbance covariance matrix, $\hat{\Sigma}$, is defined as

$\hat{\Sigma}=\left(\sum_{t=1}^{N} \hat{\varepsilon}_{i} \hat{\varepsilon}_{t}^{\prime}\right) / N$

where $\mathrm{N}$ is the sample size, and the sample disturbance, $\hat{\varepsilon}_{\mathrm{t}}$, is computed by

$\hat{\varepsilon}_{t i}=s_{i}-g_{i}(v, a)$, for $i=1,2,3$.

Maximizing the likelihood function for the system is equivalent to minimizing the generalized variance, $\mid \hat{\Sigma}\left[{ }^{25}\right.$

The estimation was accomplished using a nonlinear program (GRG2). To find a global optima, an extensive search over a large range of initial conditions was conducted. Because of the complex nonlinearity of the AIM demand system, the true maximum likelihood estimates are difficult to obtain. The possibility of missing the global optima was reduced, however, by an extensive search of the parameter space. ${ }^{26}$

All parameters are subject to non-negativity constraints to guarantee that global regularity conditions are satisfied. Because inequality constraints limit the applicability of the existing theoretical sampling distribution theory, the usual methods for testing hypotheses cannot be used. ${ }^{27}$

\section{Income Elasticities and Price Elasticities}

Because the share equations are so complex, AIM does not yield explicit functional forms for demand functions. This is the consequence for correctly embedding utility maximization into an econometrically estimable demand system that can be used to compute economically meaningful income and price elasticities.

The Allen Partial elasticities of substitution and income elasticities are defined and expressed by the following formulas: ${ }^{28}$

for $\mathrm{i} \neq \mathrm{j}$,

$\sigma_{i j}=\frac{\partial A_{i}^{c} p_{i}}{\partial p_{j} A_{i}^{c}}=\left[\frac{1}{v_{i}} \frac{\partial s_{i}}{\partial p_{f}}+\frac{s_{i}}{v_{i}}\left(\frac{1}{v_{i}} \frac{\partial s_{i}}{\partial E}+\frac{s_{i}}{p_{i}}\right] \frac{E v_{i} v_{j}}{s_{j} s_{i}}\right.$

for $i=j$,

$\sigma_{i i}=\frac{\partial A_{i}^{c} p_{i}}{\partial p_{i} A_{i}^{c}}=\left[\frac{1}{v_{i}} \frac{\partial s_{i}}{\partial p_{i}}-\frac{s_{i}}{v_{i} p_{i}}+\frac{s_{i}}{v_{i}}\left(\frac{1}{v_{i}} \frac{\partial s_{i}}{\partial E}+\frac{s_{i}}{p_{i}}\right) \frac{E v_{i}^{2}}{s^{z}}\right.$

where $p_{i}$ are the prices (and user costs), $A_{i}^{c}$ denotes the income-compensated demand functions for the $\mathrm{i}^{\text {th }}$ asset, $\mathrm{s}_{\mathrm{i}}$ denotes the expenditure shares and $\mathrm{E}$ denotes total expenditures. The elements, $o_{i j}$ constitute a symmetrical matrix called the Allen Partial matrix.

The income elasticities are defined by

$\eta_{i 0}=\frac{\partial \mathrm{A}_{\mathrm{i}} \mathrm{E}}{\partial \mathrm{E} \mathrm{A}_{\mathrm{i}}}=\frac{\partial \mathrm{s}_{i}}{\partial \mathrm{E}} \frac{\mathrm{E}}{\mathrm{s}_{\mathrm{j}}}+1$,

and the uncompensated price elasticities are denoted by
24The higher-order AlM system contains many more unknown parameters; see Barnett and Yue (1988).

25See Barnett (1981).

${ }^{26}$ To estimate parameters, $a_{i} i=1,2,3,5, \ldots, 15$, initial valtes of the unknown parameters were assigned. A number of different initial values of $\mathrm{a}_{\mathrm{i}}, 0.01,0.03,0.05,0.08$,

$0.1,0.2, \ldots, 1.0,2,0, \ldots, 10.0$ were used
27See Dufour (1989), Kodde and Palm (1986), Wolak (1989) and Barnett, Geweke and Yue (1991).

28See Diewert (1974) and Bamett and Yue (1988). 
$\eta_{\mathrm{ij}}=\frac{\partial A_{i} p_{i}}{\partial p_{i} A_{i}}=s \sigma_{i j}-s \eta_{i m}$

where $A_{4}$ are the ordinary or uncompensated demand functions. The connection between compensated and uncompensated demand functions is stated by the usual Slutsky equation.

Gross substitutability and complementarity is provided by the off-diagonal terms of the uncompensated price elasticity matrix. If $\eta_{i s}$ is positive, good $\mathrm{i}$ and good $\mathrm{j}$ are substitutes; in other words, when the price of good i rises, demand for good increases to replace a culback in demand for good i. If it is negative, they are complements-an increase in the price of good i (or i) causes the demand to fall for both goods.

Similarly, the pure substitution effects are de. fined by the Allen Partial matrix. If the utility function obeys regularity conditions, the own compensated price elasticities $\left\{\mathrm{s}_{\mathrm{i}} \mathrm{O}_{\mathrm{ij}}\right\}$ and $\left(\sigma_{\mathrm{ij}}\right\}_{\text {, }}$ must be negative. Hence, the compensated price elasticity matrix represents potential movements along the consumer's indifference curves and can be used to examine whether the estimated underlying utility function satisfies regularity conditions.

The computed elasticities of the AIM demand system are compared with other money demand systems in the next section. Because of the complexity of share equations, a numerical method is used to compute the partial derivatives of the expenditure shares with respect to prices and income that occur in the elasticity formula. The computation of elasticities is calculated using the estimated share equations. Time series of the elasticities are produced by substituting time series of normalized prices and respective partial derivatives into the elasticity formula.

\section{EMPIRICAL RESULTS OF THE AIM MONEY DEMAND SYSTEM}

In this section, the AIM demand system is estimated and the income and substitution elasticities are compared with those for the translog and Fourier demand systems. In addition, characteristics of monetary assets relative to consumer goods are analyzed.

2aDouglas Fisher provided all of the data used to estimate the AIM demand system. He had previously used these data to estimate the transiog and the Fourier demand systems. Hence, the empirical results presented here can be compared directly with his. See Fisher (1989).
Table 1

Estimates of Coefficients of the AM: 1970.1 to 1985.2

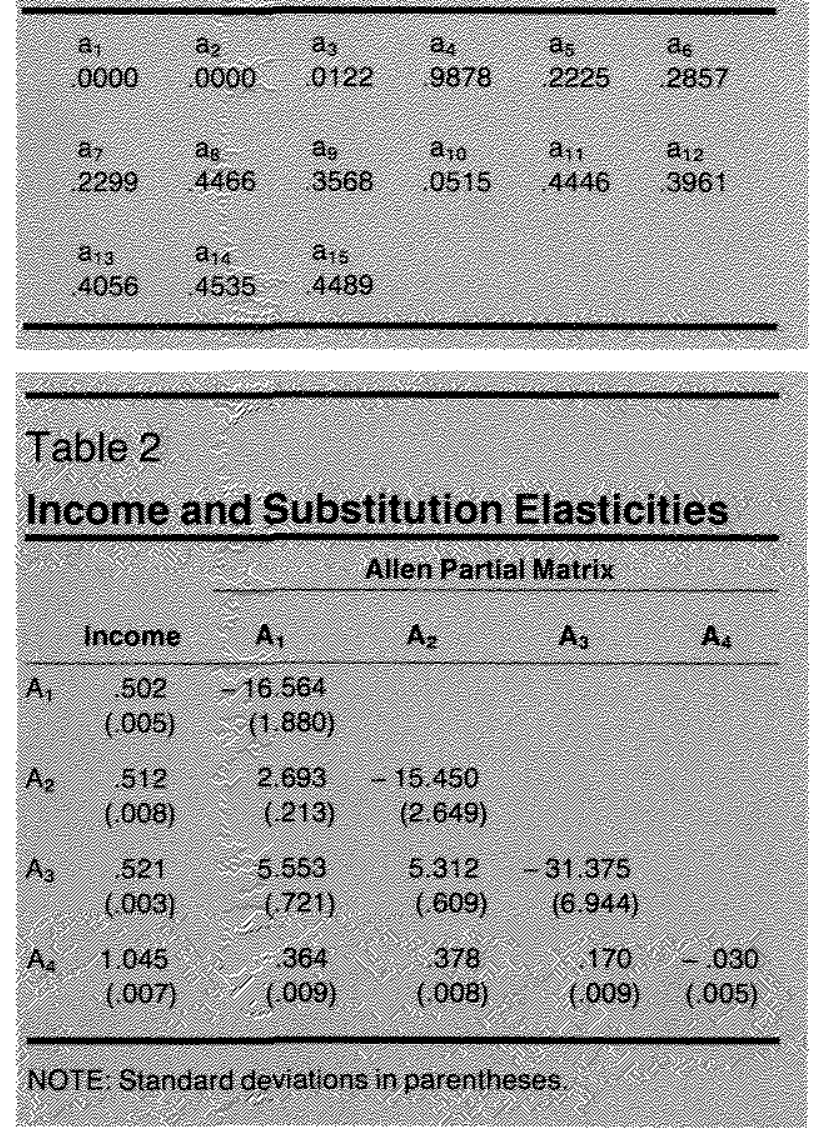

\section{Estimates of Parameters and In- come and Price Elasticities}

Table 1 displays the coefficient estimates from the AIM demand system derived by U.S. quar. terly data from 1970.1 through 1985.2..$^{29}$ These parameters represent the consumer's taste or preference and determine the utility function that underlies the estimated AIM demand sys. tem. Because the taste parameters are assumed to be constant, the consumer's utility function and preference did not change over time. The estimates of $a_{1}$ and $a_{2}$ were zero due to the non-negativity constraint. ${ }^{30}$

The estimated Allen Partial elasticities of substitution and income elasticities are reported in table 2 . The numbers represent the averages

30To this extent, the AlM model is at odds with the data because the estimated parameters would have been negative if unconstrained. 
Table 3

Income and Substitution Elasticities

\begin{tabular}{|c|c|c|c|c|c|c|c|c|c|c|}
\hline & & & ranslog & & & & & Founer & & \\
\hline & Income & 6) & As & A & 4 & Thoome & $A$ & $A_{2}$ & As & A. \\
\hline A & 8542 & 0166 & & & & 0.879 & $5-0.851$ & & & \\
\hline 4 & 8.689 & 0.490 & 0967 & & & 2714 & 1258 & -8.104 & & \\
\hline 4 & 2.741 & 0326 & 2198 & 0262 & & 2.803 & 1.119 & 2876 & -1.590 & \\
\hline A & 0707 & 0.150 & 0.805 & 6,428 & 0672 & 0.89 & 0.177 & 6.412 & 10.224 & $=0.042$ \\
\hline
\end{tabular}

and their standard deviations (in parentheses) over the sample period. Table 3 displays the estimated substitution and income elasticities from the translog and the Fourier series models previously reported by Fisher (1989, page 103).

Table 4 presents the average uncompensated price elasticities and their standard deviations over the sample period for AIM. The corresponding elasticities for the other two models are not available.

\section{What's Wrong with the Translog and Fourier Demand Systems?}

In the translog demand system results (shown in table 3), the positive sign of $\sigma_{11}$ indicates that the regularity condition is violated. This result suggests that the higher the opportunity cost of holding currency and demand deposits, the greater their demand. Given this violation of the "law of demand," the results from the translog demand system must be considered suspicious at best and, at worst, unreliable.

Problems in the Fourier series demand system cannot be seen in table 3 because the numbers reported there are the average values of these coefficients. According to Fisher, however, except for $\eta_{40}$, the income elasticities and Allen Partial elasticities of substitution changed signs frequently over the period. ${ }^{31}$ For example, in $1970, \sigma_{12}$ was significantly negative, implying complementarity; in 1971-1972, it was significantly positive, implying substitutability; and then in 1974-1975, it became negative again. Figure 1 displays a $\sigma_{12}$-comparison of the Fourier and AIM money demand systems. It is inexplica-

\begin{tabular}{|c|c|c|c|c|}
\hline \multicolumn{5}{|c|}{ Table 4} \\
\hline \multicolumn{5}{|c|}{ Uncompensated Price Elasticities } \\
\hline 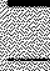 & $A_{-1}$ & $A_{2}$ & 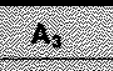 & $A_{4}$ \\
\hline$A+$ & $\begin{array}{l}534 \\
(004)\end{array}$ & $\begin{array}{r}075 \\
(010)\end{array}$ & $(084)$ & $\begin{array}{r}-126 \\
(009)\end{array}$ \\
\hline A & $\begin{array}{l}069 \\
\text { ( }\end{array}$ & $\left(\begin{array}{l}537 \\
(007)\end{array}\right.$ & $\begin{array}{l}080 \\
(010)\end{array}$ & $\begin{array}{r}123 \\
1007)\end{array}$ \\
\hline A. & $(005)$ & $\begin{array}{l}162 \\
(009)\end{array}$ & $(004)$ & $\begin{array}{l}322 \\
(004)\end{array}$ \\
\hline$A_{4}$ & $\begin{array}{l}-022 \\
(.003)\end{array}$ & $\begin{array}{r}-023 \\
(.005)\end{array}$ & $\frac{0.15}{(003)}$ & $\begin{array}{l}-985 \\
(003) \\
(003)\end{array}$ \\
\hline
\end{tabular}

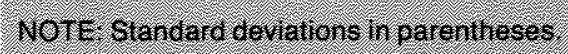

ble that currency and demand deposits, $A_{z}$, and savings deposits and money market deposit accounts, $A_{2}$, should be complements during some periods and substitutes during others.

\section{Empirical Inference of Characteristics of Monetary Assets by the AIM Demand System}

The anomalies observed with the translog and the Fourier series demand systems do not occur in the AIM demand system. The own-price elasticities are negative and all estimated elasticities maintain their signs over the entire sample period. Moreover, their smaller standard deviations indicate that they are more stable; this can also be seen in figure 1 . In the Allen Partial matrix, the diagonal elements are all negative

${ }^{31}$ See Fisher (1989), pp. 105-06. 
Figure 1

The Allen Partial Elasticity of $A_{1}$ and $A_{2}$

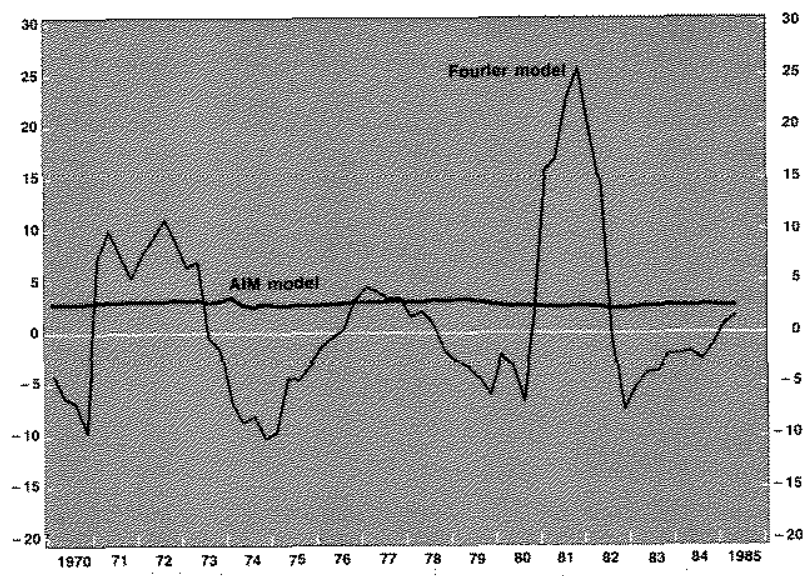

while the off-diagonal elements are positive.

This implies that the three monetary aggregates and aggregate consumption are substitutes for each other in the presence of income compensation. Moreover, the pure substitution effect between each pair of the three aggregated monetary assets is much greater than between the consumption good and monetary assets.

The income elasticities in table 2 are all positive, with the income elasticity of the consumption good about unity, and the income elasticities of the three monetary assets roughly equal to $0.5,{ }^{32}$ These results suggest that con" sumption goods and monetary assets are normal goods.

Table 4 shows that the uncompensated crossprice elasticities of $\left(A_{1}, A_{2}\right),\left(A_{1}, A_{3}\right)$ and $\left(A_{2}, A_{3}\right)$ are positive, implying that these monetary assets are gross substitutes. The uncompensated crossprice elasticities of $\left(A_{1}, A_{4}\right),\left(A_{2}, A_{4}\right)$ and $\left(A_{3}, A_{4}\right)$ are negative, indicating that consumption goods and monetary assets are gross complements.

These results show that, if the user costs of savings deposits (or money market deposit accounts, or small time depositsl rise, consumers will shift their funds to demand deposits for to checkable deposits or currency). An opposite shift of funds will take place if the user costs of currency, demand deposits and checkable deposits should rise. If these user-cost changes are sufficiently large, ignoring the cross-price effects among monetary assets will produce large errors in their demand functions.

Monetary services and consumer goods are consumed jointly. If a consumer increases the consumption of commodities for some reason, the demand for monetary assets is also increased. This is consistent with the idea that consumers hold monetary assets to finance current and future consumption. Also, the negative $\eta_{i 4}$ indicates that price inflation will reduce demand for monetary assets.

Not surprisingly, the own price elasticities of monetary assets are greater than their cross price elasticities. Similarly, it is not surprising to see that the cross price effects of a change in the price of consumption goods on the demand for monetary assets are greater than the crossprice effects of a change in the price of monetary assets on consumption. Consequently, empirical results from the AIM demand system provide a reasonable quantitative analysis of the characteristics of monetary assets-characteristics that are broadly consistent with conventional views of demand for money.

\section{A DYNAMIC ANALYSIS BY THE AIM DEMAND SYSTEM}

Constructing a dynamic model of demand for money has been difficult because the current state of economic knowledge about dynamic behavior is incomplete; the dynamics of money demand are still very much a "black box" mystery. ${ }^{33}$

Unlike most multivariate time series models, the AIM model is static. It does not consider specific dynamic effects among monetary assets and consumption goods. The utlity function is not intertemporal and its parameters are timeinvariant - the consumer's preference is not permitted to change over time.

${ }^{{ }^{3}}$ This situation occurs in a recent debate in economic literature; see Hendry and Ericsson (1991) and Friedman and Schwartz (1991).
This may not be justified by the unity income elasticity in the reduced form of the aggregate money-demand function. As pointed out in the text, no reduced form demand functions are estimated in our study and the income elasticity is defined by the microeconomic approach.

Because their income elasticities are significantly less than one, the monetary assets in our study are not "luxury goods," as has been claimed in some previous research. See Serietis (1988) 
Figure 2

Income Elasticities $E_{1}, E_{2}, E_{3}$ and $E_{4}$ for $A_{1}, A_{2}$, $A_{3}$ and $A_{4}$

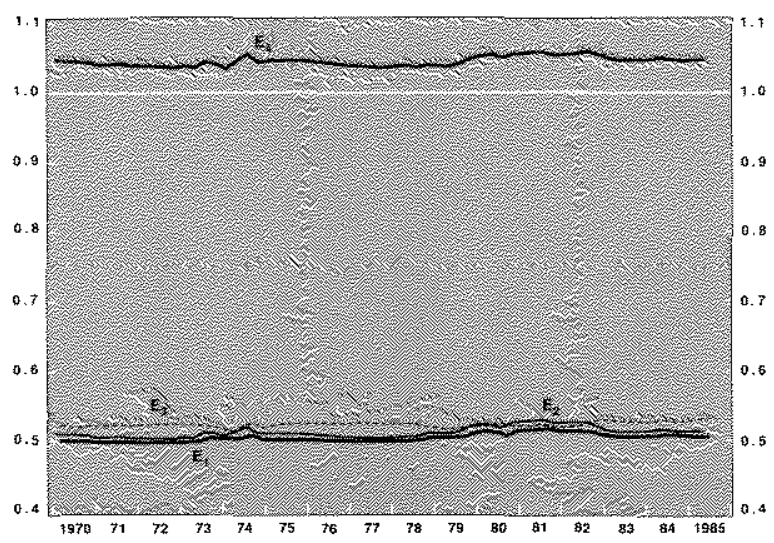

Nevertheless, a simple dynamic analysis can be used to examine the AIM demand system. Time series of income and price elasticities can be computed using estimated share equations. Movements in these elasticities reflect both changes in user costs and the consumer's reactions to such changes. Both of these are reflected in the shares, $\mathrm{s}_{\mathrm{i}}$. In this way, the dynamics of the AIM demand system can be investigated even though demand for money is stable by assumption.

This dynamic analysis is displayed in figures 2, 3 and 4 . Figure 2 shows that the income elasticities of the three monetary assets are relatively constant over the entire sample period. In contrast, the price elasticities shown in figures 3 and 4), exhibit sizable fluctuations. Major shifts in price elasticities occurred during 1973.1-1974.4 and 1978.2-1982.2. During these periods, a number of studies have reported that demand for monetary aggregate M1 was "erratic." ${ }^{34}$

Price and user cost elasticities moved drastically during these periods. In the second period (1978.2-1982.2), the cross price elasticity, $\eta_{12}$, rose by 50 percent of its 1977 level, implying that demand for $A_{1}$ (currency plus demand deposits, plus checkable deposits) became much more sensitive than it was previously to changes in the opportunity cost of holding $A_{2}$ (savings deposits and money market demand accounts). Meanwhile, there was a sharp rise in the user
Figure 3

Uncompensated Own Price Elasticities

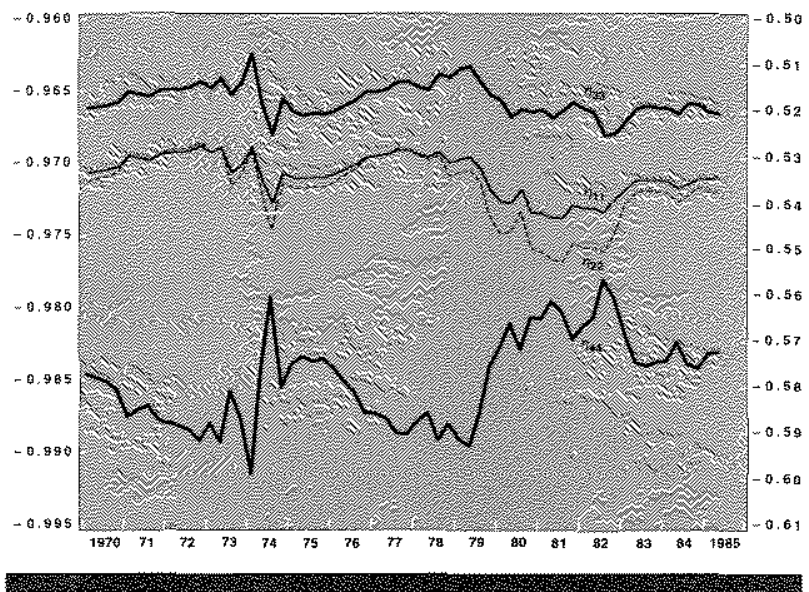

Figure 4

Uncompensated Cross Price Elasticities

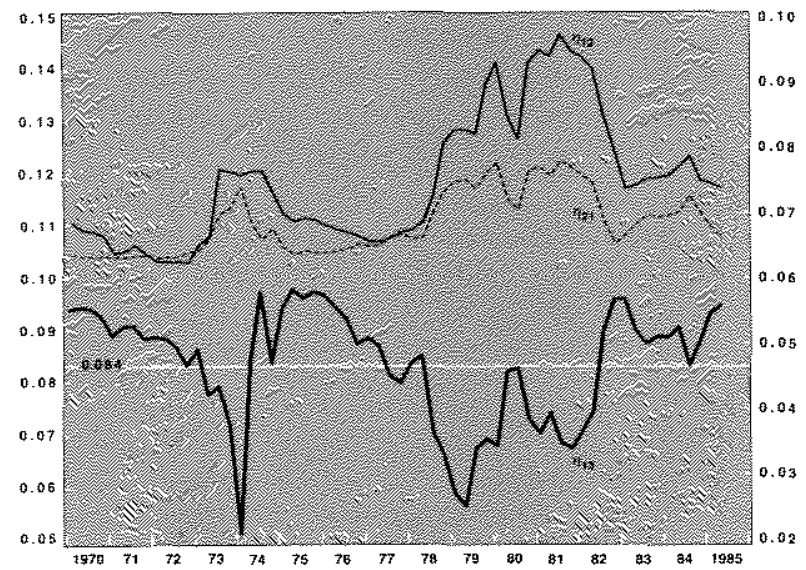

cost of $A_{2}$. These factors would appear to account for the major shift of funds from $A_{2}$ to $A_{1}$ during the period.

The opposite price elasticity, $\eta_{23}$, also rose by 20 percent. Nevertheless, it was less than 80 percent of the value of $\eta_{12}$ and the rise in the user cost of $A_{1}$ was more modest than that of $A_{2}$. It was observed that the opportunity cost of $A_{2}$ increased much faster than that of $A_{1}$. Hence, the actual flow of funds from $A_{1}$ to $A_{2}$ might not be significant.

The cross price elasticity, $\eta_{13}$, dropped 30 percent in 1979, implying that the demand for $A_{1}$

${ }^{34}$ See Goldfeld (1976) and Friedman (1984). 
was less sensitive to changes in the user cost of $A_{3}$. Hence, the shift of funds from $A_{3}$ to $A_{1}$ should have been moderate despite a substantial increase in the user cost of $A_{3}$.

These results are roughly consistent with developments during the period. In November 1978 , commercial banks were authorized to offer automatic transfer service (ATS) from savings accounts to checking accounts. Other interest ceiling-free accounts were also introduced in the early 1980s. In January 1981, Now accounts were introduced nationwide. These financial innovations should have encouraged consumers to shift funds from savings accounts and money market deposit accounts in $A_{2}$ into NOW accounts in $A_{1}$. This may have increased the interest sensitivity of demand for $A_{1}{ }^{35}$

\section{Simulating the Growth Rates of Monetary Aggregates}

A further investigation of the behavior of monetary aggregates can be made by a dynamic simulation. For example, suppose that demand for $A_{1}$ has been derived by utility maximization and expressed by the ordinary demand functions of price and user costs and total expenditure

(6) $A_{1}=G_{1}\left(u_{2}, u_{2}, u_{3}, u_{4}, E\right)$.

The total differentiation of (6) results in

(7) $\mathrm{dA}_{\mathrm{i}}=\sum_{\mathrm{j} \times 1}^{4} \mathrm{dG}_{\mathrm{i}} / \mathrm{du}_{\mathrm{j}} \mathrm{du}_{\mathrm{j}}+\mathrm{dG} / \mathrm{dE} \mathrm{dE}$.

Dividing both sides of (7) by (6) and using definitions of the uncompensated price elasticities and the income elasticity gives

(8) $\mathrm{d} A_{\mathrm{i}} / A_{\mathrm{i}}=\sum_{\mathrm{i}=1}^{4} \eta_{\mathrm{ij}}\left(\mathrm{du} / \mathrm{u}_{\mathrm{j}}\right)+\eta_{\mathrm{in}}(\mathrm{dE} / \mathrm{E})$.

Using time series of the elasticities and the growth rates of price and user costs and total expenditure, the right-hand sides of the equations in (8) are computed. In this way, the growth rates of demand for $A_{i}$ can be "simulated."

The actual and simulated growth rates of demand for monetary aggregates and consumption are displayed in figures 5 through 8 . The simulations match the actual growth rates fairly well, especially for consumption. The simulation rates of monetary assets had large fluctuations

\section{Figure 5}

Growth Rates of Aggregate $A_{1}$ Actual vs. Simulation

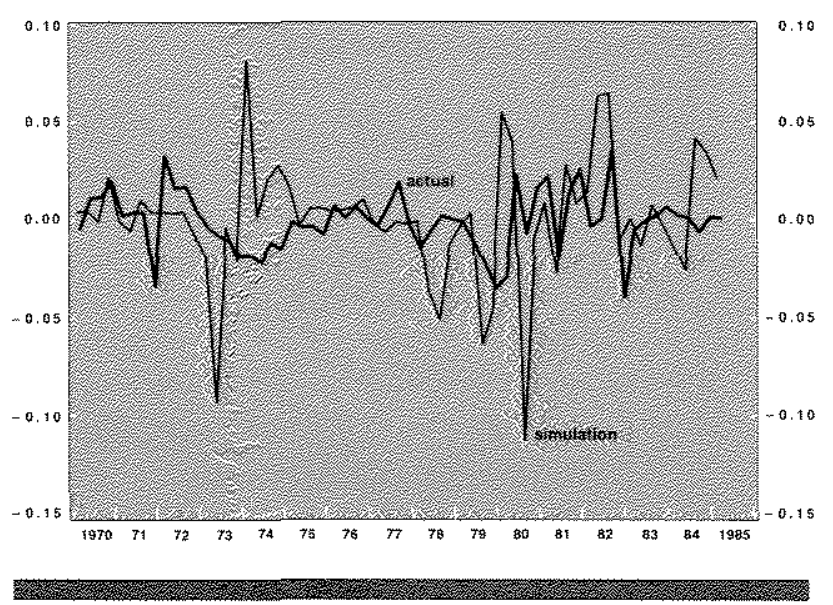

Figure 6

Growth Rates of Aggregate $A_{2}$ Actual vs. Simulation

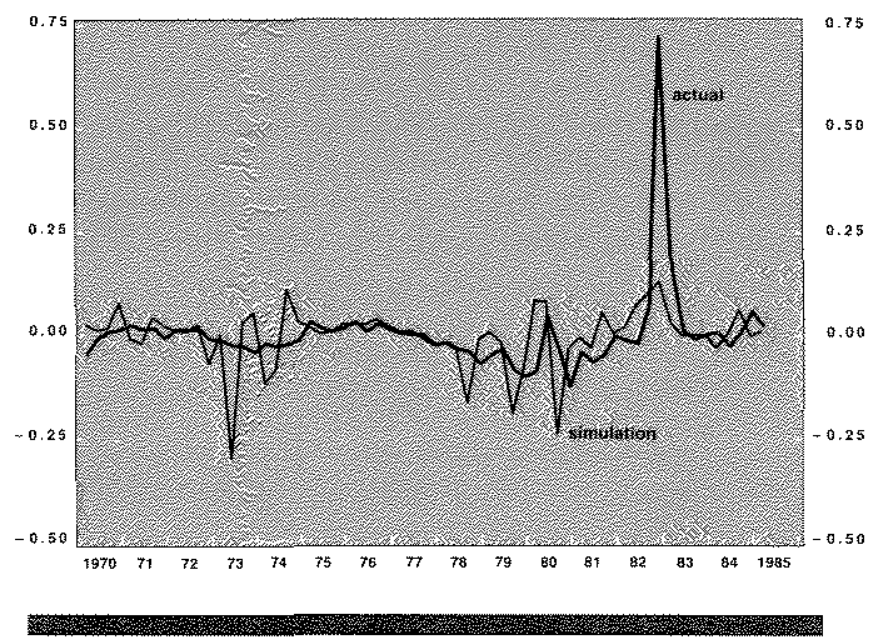

Figure 7

Growth Rates of Aggregate $A_{3}$ Actual vs. Simulation

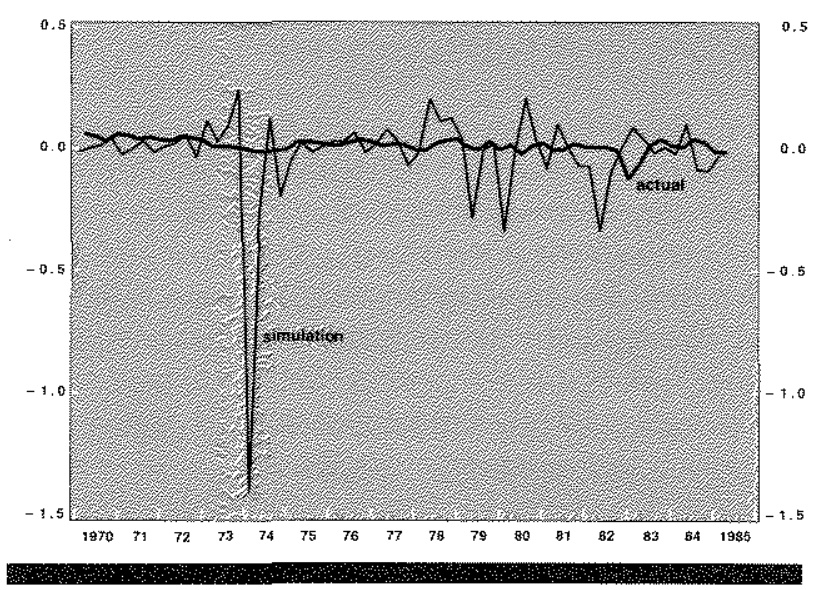

${ }^{35}$ See Thornton and Stone (1991) for a discussion of this possibility. 
Figure 8

Growth Rates of Aggregate $A_{4}$ Actual vs. Simulation

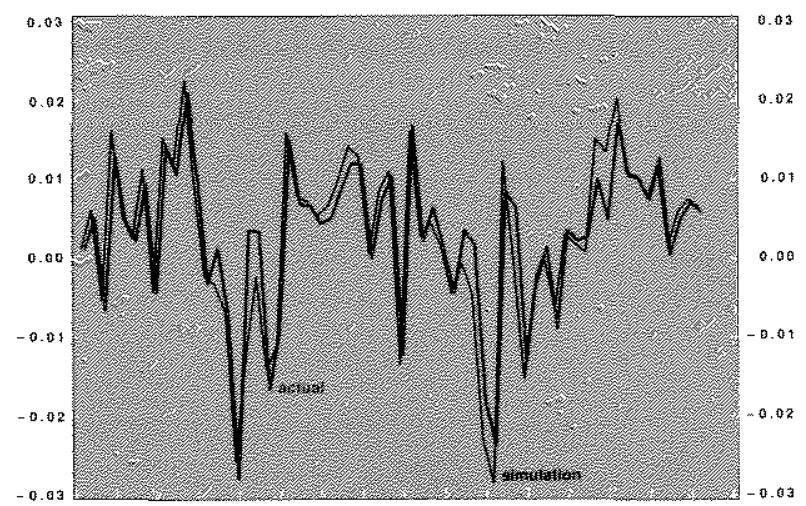

around the actual growth rates in the periods 1972.4-1975.1 and 1978.2-1982.2. Fluctuations in interest rates and inflation rates were substantial during each period, causing corresponding fluctuations in growth rates of user costs. ${ }^{36}$ These changes are reflected directly in the simulation rates.

Because the AIM model is static, sharp changes in user costs are necessarily reflected in correspondingly sharp changes in the simulated growth rates of aggregates. Hence, it is not sur. prising that the simulation errors are large during periods when there are sharp changes in user costs. Nevertheless, figures 5 through 8 suggest that the AIM demand system has captured many of the characteristics of the U.S. monetary system during the sample period.

\section{Can the AlM Demand System Ex- plain the Case of the Missing Money?}

Although the simulation of the growth rate of $A_{1}$ indicates that the AIM model produced relatively large errors during the period of "missing money" (1973.4-1976.2), an analysis of the AIM results might provide a clue. ${ }^{37}$ During this period, there was a sharp decline in demand for

${ }^{36}$ Some terms are essentially zero and can be ignored. The following growth rate equations are accurate enough to produce the simbiation:

$\mathrm{dA}_{1} / \mathrm{A}_{1}=\eta_{11} \mathrm{du} u_{1} / \mathrm{u}_{1}+\eta_{12} \mathrm{du}_{2} / u_{2}+\eta_{13} \mathrm{~d} u_{3} / u_{3}+\eta_{44} \mathrm{~d} u_{4} / u_{4}$ $+\eta_{10} \mathrm{dE} / \mathrm{E}$

$\mathrm{dA} / \mathrm{A}_{2}=\eta_{22} \mathrm{du} / \mathrm{u}_{2} / \mathrm{u}_{2}+\eta_{23} \mathrm{du} / \mathrm{u}_{3}$

$\mathrm{dA}_{3} / \mathrm{A}_{3}=\eta_{33} \mathrm{du}_{3} / \mathrm{u}_{3}$

$\mathrm{dA} / \mathrm{A}_{4}=\eta_{42} \mathrm{~d} u_{2} / \mathrm{u}_{2}+\eta_{43} \mathrm{~d} u_{3} / u_{3}+\eta_{44} \mathrm{du} / \mathrm{u}_{4} / \mathrm{u}_{4}+\eta_{10} \mathrm{dE} / \mathrm{E}$

In the equation for $A_{1}$ there are more affecting elements;

the own and cross-price effects of $A_{2}, A_{3}$ and $A_{4}$ are im-
M1; conventional money demand equations consistently overpredicted demand.

A potential explanation can be obtained by considering figures 9 and 10 . Figure 9 shows the partial derivative of demand for $A_{1}$ with respect to its own user cost. Figure 10 shows the partial derivative of demand for $A_{1}$ with respect to the user costs of $A_{2}, A_{3}, A_{4}$ and $E$. Figure 9 shows a sharp rise in the rate of change in demand for $A_{1}$ with respect to a change in its user cost. Indeed, figure 11 shows that the user cost of $A_{1}$ increased relative to the price level. Hence, the demand for $A_{1}$ should have declined by a proportionately larger amount than the rise in its user cost. Conventional linear money demand equations with fixed regression coefficients could not accommodate this nonlinearity because, in such linear demand systems, the coefficients (derivatives) are assumed to be constant. However, figures 9 and 10 clearly suggest that this is not the case. Moreover, ordinary least squares is relatively sensitive to "outliers." Consequently, there will be substantial changes in the estimated regression coefficients when the equations are estimated over periods when these derivatives change significantly.

Conventional money demand equations may be misspecified for another reason, as well. Usually they include a single short-term interest rate intended to reflect the opportunity cost of holding money. AIM analysis indicates that the demand for money does not depend on a single "representative" interest rate, but on its user cost and the user costs of "close" substitutes (recall that the demand for $A_{1}$ was sensitive to changes in the user costs of $A_{2}$ ). Hence, conventional money demand equations may produce misleading results when interest rates change relative to the user costs of $\mathrm{M} 1$ or relative to the user costs of close substitutes for M1.

Therefore, the case of "missing money" and "unexplained" parameter shifts in conventional money demand functions may result from the fact that they are essentially linear approxima-

portant in simulating the growth rate of $A_{1}$. The growth rates of demand for the other two monetary aggregates, however, are determined mainly by their own price effects and cross-price effect, $\eta_{23}$. This suggests that ignoring the substitution effects of non-M1 components of M2 might be one of the factors that discredit reliability of the conver:tional M1 demand function.

${ }^{37}$ See Goldfeld (1976). 
Figure 9

The First Derivative of $A_{1}$ with Respect to Own User Cost

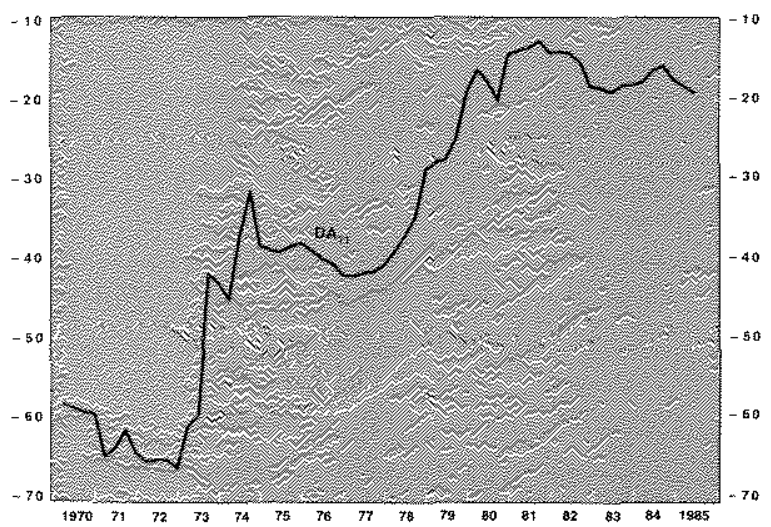

Figure 10

The First Derivatives of $A_{1}$ with Respect to User Costs, Price and Income

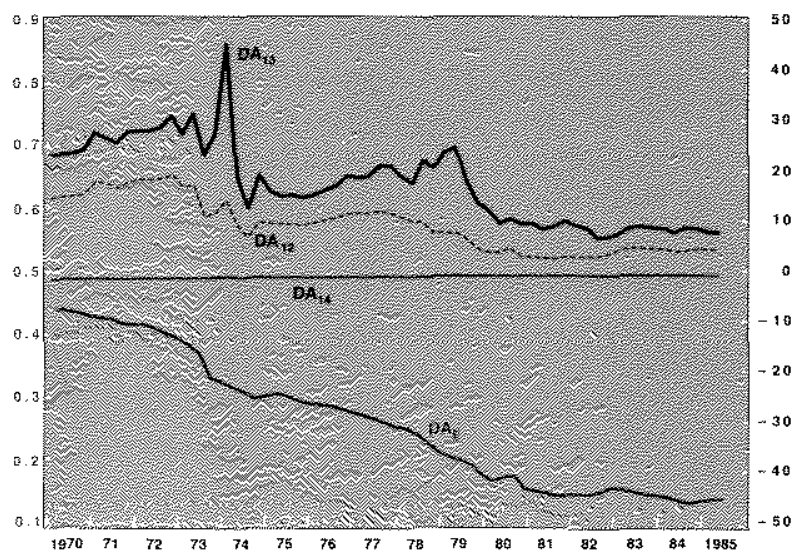

tions to nonlinear demand functions. If so, they intuitively will provide mueh poorer approximations during periods when there are dramatic changes in user costs.

\section{Is The Money Demand Mrection Stable?}

The erratic behavior of conventional money demand functions and, more recently, the income velocity of M1, have led many researchers to assert that the demand for money is "unsta-
Figure 11

User Cost of $A_{1}$ vs. Price of $A_{4}$

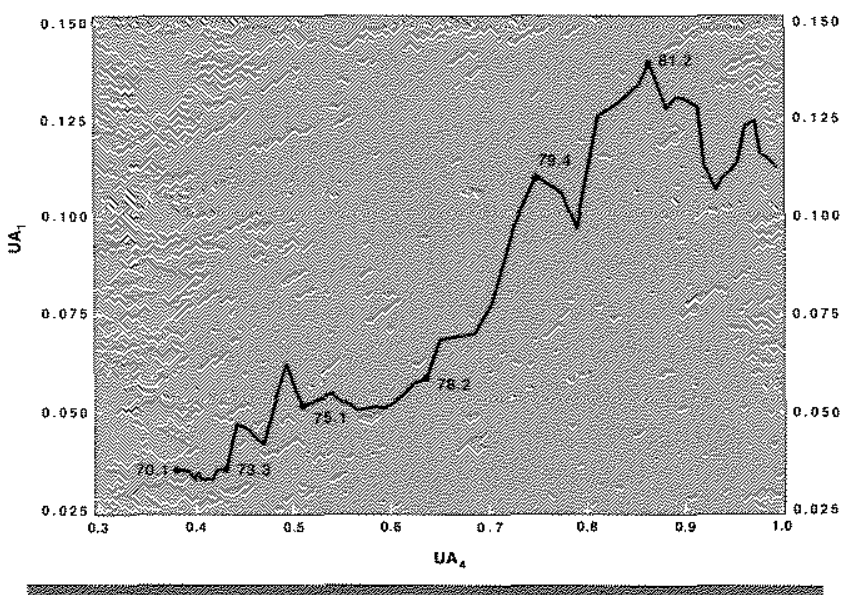

ble," 3 others have asserted that money demand is stable based on the observed stability of the consumption function. ${ }^{39}$

The AlM demand system integrates demand for both consumption and money and then estimates them simultaneously. These estimates suggest that, while the own price and cross price elasticities show considerable variation due to changes in the price level and user costs, they change little on average over the period (see figures 3 and 4) ${ }^{40}$ Moreover, the estimated income elasticities for all three monetary aggregates are nearly constant (see figure 2). Of course, these results are obtained from a model where the estimated parameters are time-invariant, that is, the preference function is constant. Because of this, it is necessarily true that demand functions are "stable." Nevertheless, the relatively good performance of AIM provides some promise that, like consumption, the demand for money will ultimately be showr to be a stable function of a relatively few economic variables-in this case, income and user costs.

\section{CONCLUSTON}

Two distinctly different micromeconometric demand system approaches to the demand for money were presented and discussed. An ad. vanced AIM demand system was presented and estimated using U.S. time-series data. Unlike

ing. However, no formal tests of stationarity were performed in this study.

38For a discussion of the velocity of $\mathrm{M} 1$ and an analysis of some of the explanations, see Stone and Thornton (1987).

39For example, see Friedman (1956) and Lucas (1988).

40 In the parlance of modern time-series analysis, these elasticities are said to be stationary, that is, mean revert- 
other utility function-based approaches, AIM estimates are consistent with microeconomic theory. Dynamic simulations of the growth rates of various monetary aggregates and consumption suggest that the estimated AIM model performed well; nevertheless, the largest simulation errors occurred in periods when there were relatively sharp swings in user costs or inflation. This is perhaps not too surprising given the static nature of the AIM analysis.

An analysis of changes in income and cross price elasticities are suggestive of portfolio shifts among monetary aggregates in the 1970 s and 1980 s consistent with the observed behavior of these aggregates. The results of AIM suggest that the reported failure of conventional linear (or log-linear) money demand equations may result from trying to fit fundamentally nonlinear functions with linear ones. The results shown here suggest that this problem will be particularly acute whenever there are sharp changes in user costs. Unfortunately, these are precisely the times when AIM performance was also poor. The key to solving this problem in AIM, however, is to find a way to make AIM explicitly dynamic. It may not be necessary to assume that consumer preferences are unstable.

The sampling distribution theory for AIM has not been worked out at this time, so relevant hypothesis tests cannot be conducted yet. Also, because the time series on the relevant user costs of monetary aggregates is limited, the available data cover a relatively short sample period. These factors, coupled with the fact that even low-order (first-order) AIM systems require a relatively large number of estimated parameters, place severe limits on attempts to evaluate the performance of AIM using out-of-sample forecasts. Despite these problems, the estimated AIM system appears to have captured many of the characteristics of monetary assets and offers some useful explanations to puzzling empirical issues. Hence, these results are encouraging to those who believe that microeconomic principles, such as utility maximization, can be applied usefully to macroeconomic problems.

\section{RERTRENCES}

Barnett, Wallam A. Consumer Demand and Labor Supply (Amsterdam: North-Holland, 1981).

"New Indices of Money Supply and the Flexible Laurent Demand System:" Journal of Business and Economios Statistics (January 1983): pp. $7-23$.
Barnett, William A., and Andrew B. Jonas. "The MuntzSzatz Demand System: An Application of a Globally Well Behaved Series Expansion;" Economics Letters Vol. 11, No.4 (1983), pp. 337-42.

Barnett, William A., John Geweke, and Piyu Yue, "Serminonparametric Bayesian Estimation of the Asymptotically Ideal Model: the AIM Consumer Demand System," in William Bannett, James Powell, and George Tauchen, eds., Nonparametric and Seminonparametric Methods in Econometrics and Statistics, Proceedings of the Fifth International Symposium in Economic Theory and Econometrics (Cambridge University Press, 1991).

Barnett, Wiltam A., and Piyu Yue. "Seminonparametric Estimation of the Asymptotically Ideal Model: the AIM Demand System," in George Rhodes and Thomas Fomby, eds., Nonparametric and Robust Inference, Advances in Econometrics, volume 7 (1988), pp. 229-51.

Diewert, W. E. "Applications of Duality Theory," in Michael D. Intriligator and David A. Kendrick, eds., Frontiers of Quantitative Economics, Vol. II (Amsterdam: North-Holland, 1974), pp. 106-71.

Dlewert, W. E., and T. J. Wales. "Flexible Functional Forms and Global Curvature Conditions," Econometrica (January 1987), pp. 43-68.

Dufour, Jean-Marie. "Nonlinear Hypotheses, Inequality Res" trictions, and Non-Nested Hypotheses: Exact Simultaneous Tests in Linear Regressions, ${ }^{* 1}$ Econometrica (March 1989) pp. 335-56.

Fayyad, Salam K. "A Microeconomic System-Wide Approach to the Estimation of the Demand for Money." this Review (August/September 1986), pp. 22-33.

Feenstra, Robert C. "Functional Equivalence Between Liquidity Costs and the Utility of Money," Journal of Monetary Economics (March 1986), pp. 271-91.

Fisher, Douglas. Money Demand and Monetary Policy (The University of Michigan Press, 1989).

Friedman, Benjamin. "Lessons From the 1979-82 Monetary Policy Experiment," American Economic Review (May 1984), pp. 382-87.

Friedman, Milton. "The Quantity Theory of Money-A Restatement," in Milton Friedman, ed., Studies in the Quantity Theory of Money (University of Chicago Press, 1956).

Friedman, Milton, and Anna J. Schwartz. "Alternative Approaches to Analyzing Economic Data," The American Economic Review (March 1991), pp. 39-49.

Gallant, A. Ronald. "On the Bias in Flexible Functional Forms and an Essentially Unbiased Form: The Fourier Flexible Form," Joumal of Econometrics (February 1981), pp. $211+45$.

"The Fourier Flexible Form," American Journal of Agricultural Economics (May 1984), pp. 204-08.

Gallant, A. Ronald, and Douglas W. Nychka, "SemiNonparametric Maximum Likelihood Estimation," Econometrica (March 1987), pp. 363-90.

Goldfeld, Stephen M. "The Case of the Missing Money," Brookings Papers on Economic Activity (3:1976), pp. $683-739$.

Mendry, David F., and Neil R. Ericsson. "An Econometric Analysis of U.K. Money Demand in Monetary Jrends in the United States and the United Kingdom by Miton Friedman and Anna J. Schwartz," American Economic Review (March 1991), pp. 8-38.

Judd, John P., and John L. Scadding. "The Search for a Stable Money Demand Function: A Survey of the Post-1973 Literature," Joumal of Economic Literature (September 1982), pp. 993-1023. 
Kodde, David A., and Franz C. Palm. "Wald Criteria for Joint" ly Testing Equality and Inequality Restrictions," Econometrica (September 1986), pp. 1243-48.

Lasdon, Leon S., and A. D. Warren. "GRG2 User's Guide" University of Texas at Austin, 1989.

Lucas, Robert E., Jr. "Money Demand in the United States: A Quantitative Review," Carnegie-Rochester Conference Series on Public Policy No. 29, (Autumn 1988), pp. 137-68.

Mankiw, N. Gregory. "A Quick Refresher Course in Macroeconomics", Journal of Economic Literature (December 1990), pp. 1645-60.

Moore, George R., Richard D. Porter, and David H. Small. "Modeling the Disaggregated Demands for M2 and M1: The U.S. Experience in the 1980s," in Peter Hooper and others, eds., Financial Sectors in Open Economies: Empirical Analysis and Policy issues (Board of Governors of the Federal Reserve System, 1990), pp. 21-97.

Pierce, James L. "Did Financial Innovation Hurt the Great Monetarist Experiment?" American Economic Review (May 1984), pp. 392-96.

Rasche, Robert H. "Demand Functions for Measures of U.S. Money and Debt," in Peter Hooper and others, eds., Financial Sectors in Open Economies: Empirical Analysis and Policy Issues (Board of Governors of the Federal Reserve System, 1990), pp. 113-61.
Serletis, Apostolos. "Translog Flexible Functional Forms and Substitutability of Monetary Assets," Journal of Business and Economic Statistics (January 1988), pp. 59*67.

Stone, Courtenay C., and Daniel L. Thornton. "Solving the 1980 s Velocity Puzzle: A Progress Report," this Review (August/September 1987), pp. 5-23.

Swoftord, James L, and Gerald A. Whitney, "Flexible Functional Forms and the Utility Approach to the Demand for Money: a Nonparametric Analysis": Journal of Money, Credit and Banking (August 1986), pp. 383-89.

Telser, Lester G., and Robert L. Graves. Functional Analysis in Mathematical Economics (The University of Chicago Press, 1972).

Thomton, Daniel L., and Courtenay $\mathrm{C}$. Stone. "Financial Innovation: Causes and Consequences," in Kevin Dowd and Mervyn K. Lewis, eds., Current issues in Monetary Analysis and Policy (MacMillan Publishers, 1991).

Uzawa, Hirofumi, "Production Functions with Constant Elasticities of Substitution," Review of Economic Studies (October 1962), pp. 291-99.

Wolak, Frank A. "Local and Global Testing of Linear and Nonlinear Inequality Constraints in Nonlinear Econometric Models," Econometric Theory (April 1989), pp. 1-35. 